\title{
Reconhecimento e análise das fácies sísmicas nas sucessões rift das bacias de Campos e Santos
}

\author{
Renata ALVARENGA ${ }^{1}$, Juliano KUCHLE ${ }^{2}$, David IACOPINI ${ }^{3}$, Patrycia ENE ${ }^{1}$, Claiton SCHERER ${ }^{4}$ \& \\ Karin GOLDBERG ${ }^{5}$
}

(1) Programa de Pós-graduação em Geociências, Instituto de Geociências, Universidade Federal do Rio Grande do Sul. Av. Bento Gonçalves, 9500, CEP 91501-970, Porto Alegre, Rio Grande do Sul, Brasil. E-mail: renatalvarenga@yahoo.com.br, patrycia.n@gmail.com.

(2,4) Departamento de Palentologia e Estratigrafia, Instituto de Geociências, Universidade Federal do Rio Grande do Sul. Av. Bento Gonçalves, 9500, CEP 91.540-000, Porto Alegre, Rio Grande do Sul, Brasil. E-mail: juliano.kuchle@ufrgs.br, claiton.scherer@ufrgs.br.

(3) Geology and Petroleum Geology, University of Aberdeen. AB24 3UE, Aberdeen, UK. E-mail: d.iacopini@abdn.ac.uk.

(5) Departamento de Mineralogia e Petrologia, Instituto de Geociências, Universidade Federal do Rio Grande do Sul. Av. Bento Gonçalves, 9500, CEP 540-000, Porto Alegre, Rio Grande do Sul, Brasil. E-mail: karin.goldberg@ufrgs.br.

Recebido em 08/2015. Aceito para publicação em 07/2016.

Versão online publicada em 26/08/2016 (www.pesquisasemgeociencias.ufrgs.br)

\begin{abstract}
Resumo - Apresentando reservatórios em águas profundas, o pré-sal das bacias de Campos e Santos é um cenário com depósitos heterogêneos e complexos, e assim traz novos desafios para a interpretação sísmica. 0 presente trabalho tem como objetivo a caracterização sísmica do intervalo rifte (de idade Hauteriviano Superior ao Barremiano, imediatamente abaixo dos reservatórios pré-sal) nas bacias de Campos e Santos com a utilização de dados de sísmica 2D e dois perfis de poços. Foram analisadas as texturas sísmicas e com a integração dos dados litológicos se definiu três sismofácies correspondentes: Sismofácies 1 (depósito de falha de borda) - apresenta comportamento semelhante em ambas as bacias e com ocorrência encaixada na falha de borda em uma zona ampla e bem definida; Sismofácies 2 (depósito de sedimentos finos) - amplamente identificada nas bacias de Campos e Santos e que grada lateralmente para a sismofácies 3; Sismofácies 3 (depósito de grainstones e rudstones) - em ambas as bacias têm ocorrência restrita e de ocorrência errática, tanto em zonas altas da margem flexural, quanto nas zonas profundas próximas do depocentro dos meio-grábens analisados.
\end{abstract}

Palavras - chave: Bacia rifte, atributos sísmicos, texturas sísmicas.

\begin{abstract}
RECOGNITION AND ANALYSIS OF SEISMIC FACIES IN THE RIFT SUCCESSIONS OF THE CAMPOS AND SANTOS BASINS. With deep-water reservoirs, the pre-salt scenario in Campos and Santos basins setting heterogeneous and complex deposits, and thus brings new challenges for seismic interpretation. This study aims at the seismic characterization of the rift section (Upper Hauterivian to Barremian, immediately below the pre-salt reservoirs) in the Campos and Santos basins, with the use of 2D seismic data and two well logs. We analyzed the seismic textures, and the integration of lithologic data defined the corresponding to three seismic facies: Seismic facies 1 (fault-border deposits) displays similar behavior in both basins, with occurrence restricted to the fault borders in a wide and well-defined area; Seismic facies 2 (fine-grained deposits) is widespread in the Campos and Santos basins and grades laterally to seismic facies 3; Seismic facies 3 (grainstone and rudstone deposits) has restricted and erratic occurrence in both areas of the high flexural margin, as well as in the deep areas near the depocenter of the analyzed half-grabens.
\end{abstract}

Keywords: Rift basin, seismic attributes, seismic texture.

\section{Introdução}

Nas últimas três décadas houve um crescente aprimoramento dos conhecimentos e métodos para aquisição e processamento de dados sísmicos, permitindo o reconhecimento de feições geológicas em várias escalas através da interpretação dos padrões de reflexão sísmica. Além disso, houve uma ampliação na construção de conceitos, tais como (i) textura sísmica, definida como uma variação da amplitude de reflexão, fase e frequência padrão combinados em um dado local num volume sísmico (Gao, 2003), e (ii) fácies sísmica, que é definida como uma unidade sísmica tridimensional mapeável, composta por grupos de reflexões cujos parâmetros (amplitude, geometria, continuidade e 
frequência) diferem dos parâmetros das unidades vizinhas (Prather et al., 1998; Posamantier et al., 1988). 0 conceito de fácies sísmica tem sido tradicionalmente ligado a um contexto de interpretação geológica, enquanto, o conceito de textura sísmica, deriva do domínio da análise de imagem bidimensional (2D), desenvolvido na década de 70 por Haralick et al. (1973), Weszka et al. (1976), Reed \& Hussong (1989) e, em seguida, aplicado à reflexão sísmica (Zhang \& Simaan, 1989, Vinther et al., 1995; Gao, 2003; 2007). Textura sísmica é uma propriedade estritamente relacionada ao reconhecimento de certas características sísmicas, utilizando as relações de amplitude e fase, repetidas através de um conjunto de dados de volume 3D e sísmica 2D. As texturas sísmicas podem ser calibradas com a utilização de perfis de poços, ou mesmo com informações litológicas, proporcionando desta forma uma melhor robustez ao modelo. 0 uso de atributos sísmicos, tais como, cosseno da fase, Amplitude RMS, Sweetness e Impedância acústica relativa têm desempenhado um papel fundamental na análise das texturas sísmicas. Esses atributos permitem o realce de feições estratigráficas e estruturais para o mapeamento de falhas e contatos litológicos.

O intervalo rifte nas bacias de Campos e Santos inclui rochas ricas em matéria orgânica que são geradoras dessas bacias, e rochas carbonáticas que são os reservatórios (Winter et al., 2007; Moreira et al., 2007). Com o objetivo de discriminar as sismofácies relacionadas com as rochas carbonáticas, daquelas vinculadas a sedimentos finos, ricas em matéria orgânica, foi realizada uma interpretação das texturas sísmicas com a análise das configurações, continuidade, amplitude e frequência dos refletores. Desta forma, foram estabelecidas as texturas sísmicas e com a utilização dos dados litológicos foi possível a amarração com a sísmica para a identificação das sismofácies.

\section{2 Área, materiais e métodos}

\subsection{Contexto geológico}

As bacias de Campos e Santos estão localizadas na margem leste brasileira, se estendem do sul do Estado do Espírito Santo, pelo alto de Vitória até a Plataforma de Florianópolis. Juntas recobrem uma área de $465.800 \mathrm{Km}^{2}$, em frente ao litoral do Rio de Janeiro, São Paulo, Paraná e norte de Santa Catarina (Fig. 1). Basicamente, as bacias de Campos e Santos apresentam uma evolução geológica geral semelhante às outras bacias da margem atlântica brasileira (Milani \& Thomaz Filho,
2000), com uma fase rifte, de idade hauteriviana a aptiana: rochas vulcânicas, e sedimentos clásticos de idade barremiana a aptiana, sucedidos por um espesso pacote de evaporitos aptianos, usualmente alóctones, na forma de domos, muralhas e diápiros, compreendendo a fase "sag/transicional" (Moreira et al., 2007; Winter et al., 2007). Por fim, a fase de margem intraplaca inicia-se com uma sucessão dominantemente carbonática de idade albiana, interpretada como uma rampa carbonática, e uma fase oceânica com quebra de plataforma, do Cenomaniano ao Recente, compreendendo sedimentos clásticos grossos proximais e carbonáticos plataformais, clásticos finos distais e clásticos grossos turbidíticos.

Nas bacias de Campos e Santos são reconhecidas falhas normais lístricas e de alto ângulo que afetam a crosta continental, rochas vulcânicas do Barremiano ao início do Aptiano e depósitos clásticos; domos do sal no talude continental; falhas normais lístricas e inversas associadas com a movimentação do sal afetam os sedimentos do Cretáceo Superior e do Terciário; falhas limitando meio-grábens causados pela fase distensional entre o Hauteriviano e Barremiano Superior (Chang et al., 1992).

As informações litológicas da Bacia de Campos seguem a última atualização da carta estratigráfica que foi realizada por Winter et al. (2007). A supersequência rifte da Bacia de Campos corresponde à Formação Cabiúnas e à porção inferior do Grupo Lagoa Feia (formações Atafona, Coqueiros e Itapaboana). A Formação Atafona foi depositada no Andar Barremiano (andares locais Aratu superior e Buracica), a Formação Coqueiros tem idade do Barremiano superior ao Aptiano inferior (andar local Jiquiá), e a Formação Itapaboana do Barremiano ao Aptiano inferior. 0 Grupo Lagoa Feia é caracterizado por sedimentos siliciclásticos, carbonáticos e evaporíticos depositados durante a fase rifte e pós-rifte (Fig. 2). Segundo Guardado et al. (2000), as espessuras deste pacote variam de 200 $\mathrm{m}$ para mais de $1.500 \mathrm{~m}$, tendo sido depositado em ambiente continental. 0 Grupo Lagoa Feia é composto pelas formações Atafona, Itapaboana, Coqueiros, Macabu, Gargaú e Retiro. A Formação Atafona é constituída por arenitos, siltitos e folhelhos depositados em ambiente lacustre alcalino onde se precipitaram minerais de talco e estevensita. A Formação Coqueiros é representada por depósitos de coquinas compostos predominantemente por moluscos bivalves, intercalados com folhelhos e carbonatos lacustres. Segundo Baumgarten et al. (1988), os depósitos de coquinas são compostos por ciclos deposicionais de fácies de calcirrudito, 


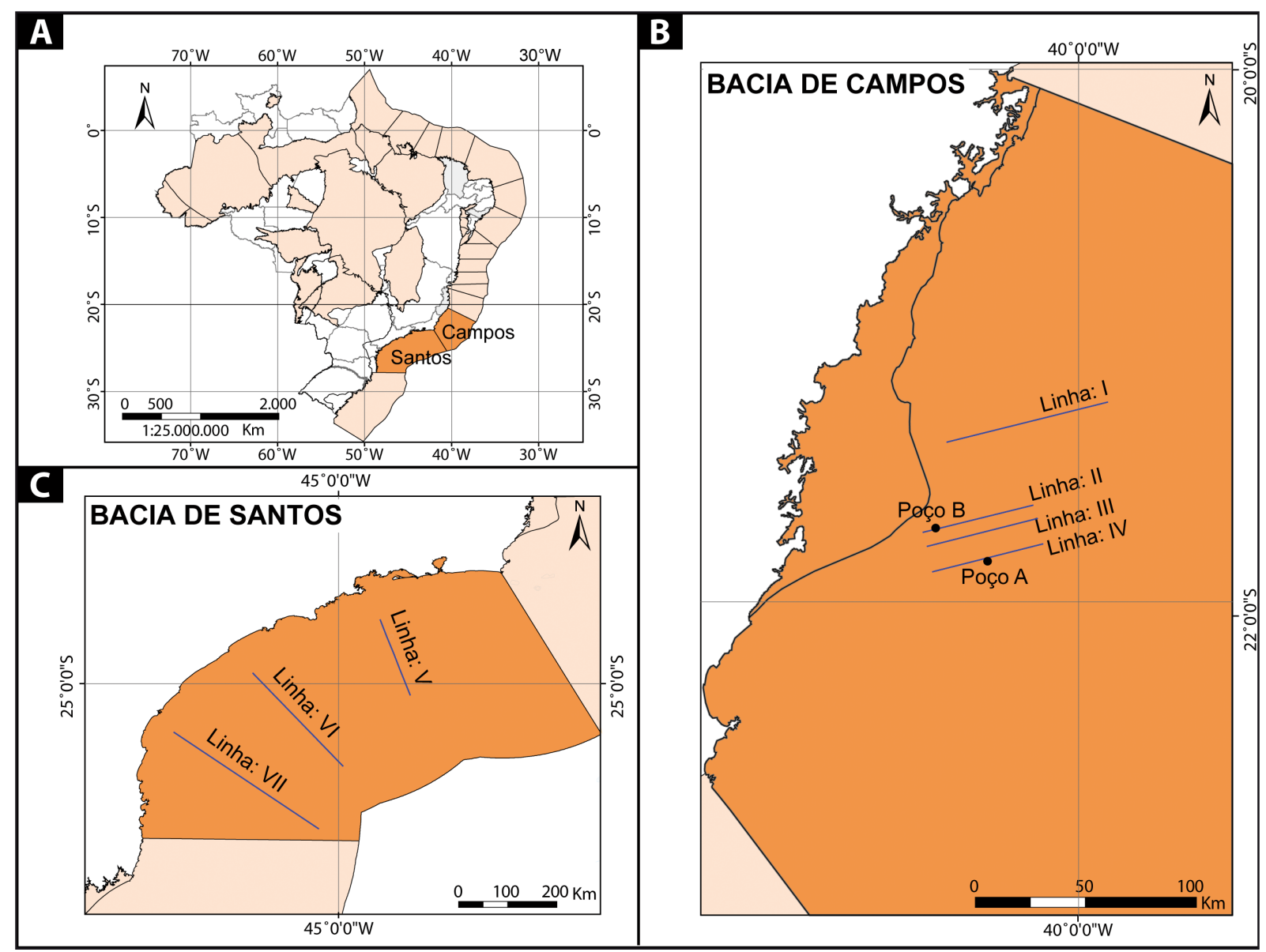

Figura 1. Localização das bacias. A) Localização das bacias de Campos e Santos no Brasil. B) Localização das linhas sísmicas na Bacia de Campos. C) Localização das linhas sísmicas na Bacia de Santos. Fonte: Banco de dados BDEP.

calcarenito, calcilutito e aleatoriamente fácies de bioacumulados, podendo formar pacotes com espessuras maiores que $100 \mathrm{~m}$. A Formação Itapaboana é composta por conglomerados, arenitos, siltitos e folhelhos depositados nas porções proximais da bacia e ao longo da falha de borda. As formações Macabu e Gargau são constituídas por sedimentos carbonáticos, margas e arenitos, depositados em ambiente transicional raso. A Formação Retiro é caracterizada por depósitos evaporíticos compostos por anidrita, halita e carnalita/silvita depositadas em ambiente marinho/lagunar sob clima árido. As camadas de halita ocorrem remobilizadas, originando domos de sal que cortam as camadas sobrejacentes (Rangel et al., 1994). A porção superior do Grupo Lagoa Feia (formações Gargaú, Macabu, Retiro e Itapaboana superior) foi depositada já na fase sag/transicional (carta estratigráfica de 1994), ou já considerada pós-rifte por Winter et al. (2007) da Bacia de Campos. Este estudo de Winter et al. (2007), com sua abordagem litoestratigráfica do Grupo Lagoa Feia, compreende um certo empilhamento em forma de layer cake das formações Cabiúnas, Atafona, Coqueiros, Macabu e Retiro, com gradações laterais apenas para as formações Itabapoana e Gargaú. Entretanto, os indícios das sismofácies apresentam uma disposição espacial mais complexa.

Na Bacia de Santos, a supersequência rifte inicia no Hauteriviano e prolonga-se ao início do Aptiano. Na base deste intervalo ocorre a Formação Camboriú que é composta por derrames basálticos eocretáceos sotopostos ao preenchimento sedimentar de praticamente toda a Bacia de Santos, e é crono e lito correlata com a Formação Cabiúnas de Campos. A Formação Piçarras é composta por leques aluviais de conglomerados e arenitos polimíticos constituídos de fragmentos de basalto, quartzo, feldspato, nas porções proximais, e por arenitos, siltitos e folhelhos de composição talco-estevensítica nas porções lacustres. A Formação Itapema (Grupo Guaratiba) é caracterizada por apresentar intercalações de calcirruditos e folhelhos escuros ricos em matéria orgânica nas porções mais distais, conglomerados e arenitos de leques aluviais nas porções proximais desta unidade (Moreira et al., 2007). A figura 3 apresenta a supersequência rifte, com as formações correspon- 
dentes às sequências deposicionais, e informações acerca da tectônica e magmatismo, geocronologia e ambiente deposicional. De certa forma, as Formações Piçarras, Itapema e Barra Velha compreendem depósitos semelhantes das formações Atafona, Coqueiros e Macabu da Bacia de Campos, e esta forma litoestratigráfica simplificada da Bacia de Santos deve-se ao seu menor período exploratório quando comparado com a Bacia de Campos, o que resulta em uma menor quantidade de poços e informações litológicas disponíveis.

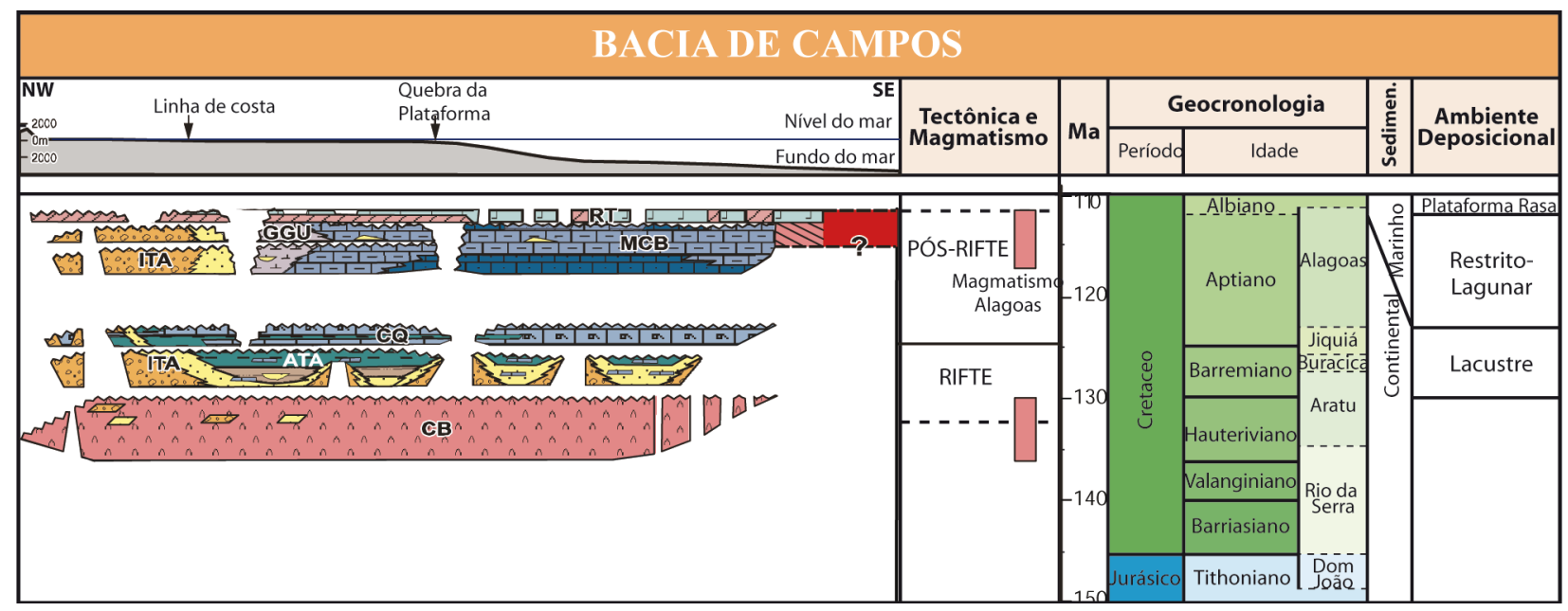

Figura 2. Carta estratigráfica da seção rifte da Bacia de Campos (modificada de Winter et al., 2007). Legenda: Formação Cabiúnas (CB), Formação Itapaboana (IATA), Formação Atafona (ATA), Formação Coqueiros (CQ), Formação Garagaú (GGU) e Formação Macabu (MCB).

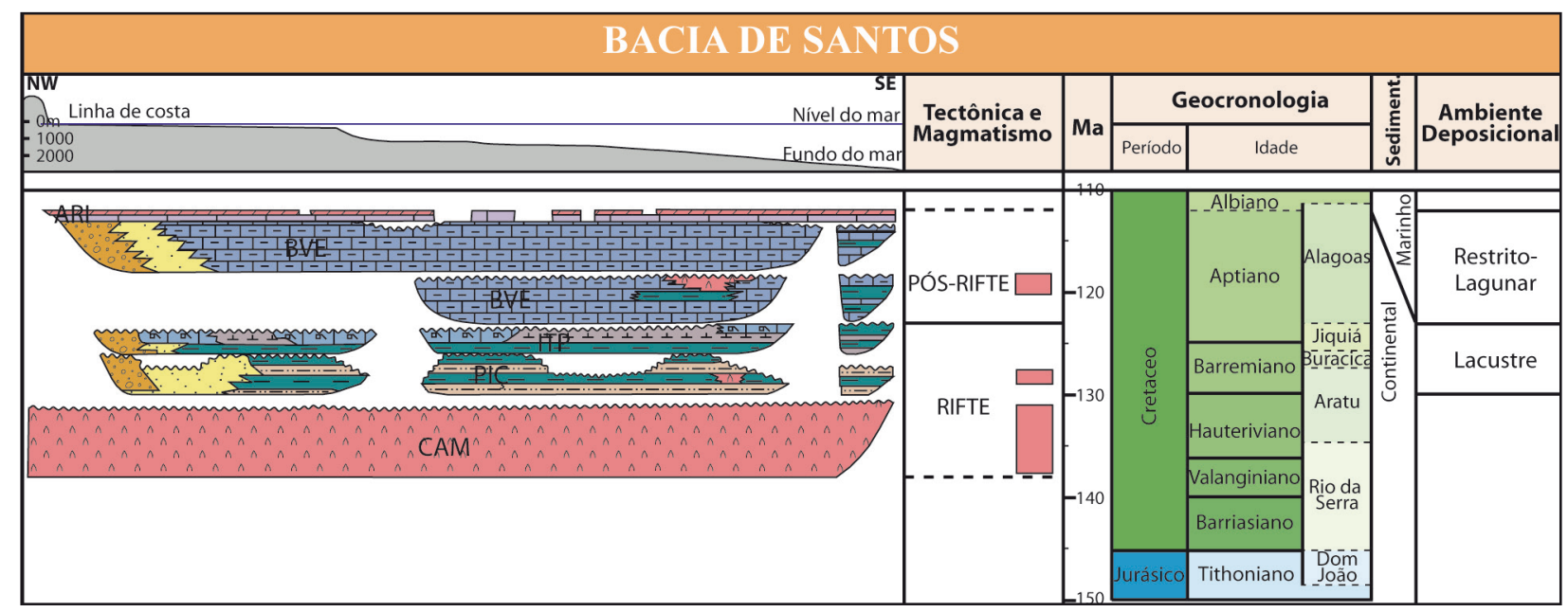

Figura 3. Carta estratigráfica da seção rifte da Bacia de Santos (modificada de Moreira et al., 2007). Legenda: Formação Camboriú (CAM), Formação Piçarras (PIÇ), Formação Itapema (ITP), Formação Barra Velha (BVE) e Formação Ariri (ARI).

\subsection{Dados e métodos}

A base de dados utilizada foi constituída por uma série de levantamentos sísmicos 2D adquiridos nas décadas de 1980 a 1990, considerados dados de acesso público no Brasil, e disponibilizados pela Agência Nacional do Petróleo, resultando em um total de 282 linhas sísmicas, além de 40 poços, sendo apenas $13 \mathrm{com}$ testemunhos. Deste total foram utilizadas sete linhas sísmicas resultando em $250 \mathrm{~km}$ e dois poços (A e B) para balizar os dados litológicos com os dados sísmicos. Os métodos utilizados consistiram na aplicação de atributos sísmicos para reconhecimento e mapeamento das sismofácies. Atributos sísmicos são recursos aplicados em dados sísmicos a fim de realçar feições estratigráficas, litológicas e estruturais. 0 intervalo analisado na sísmica 2D compreende algumas feições estruturais e contatos litológicos difíceis de serem caracterizados sem o subsídio de atributos sísmicos. Desta forma, visando à caracterização es- 
trutural e estratigráfica foram aplicados os seguintes atributos: cosseno da fase, Sweetness, amplitude RMS e impedância acústica relativa.

\subsection{Atributos sísmicos}

Os atributos sísmicos são calculados através do uso de várias propriedades analíticas e assim têm a capacidade de destacar a geometria dos refletores. Desta forma, foram aplicados os seguintes atributos: cosseno da fase, Sweetness, impedância acústica relativa e amplitude RMS. 0 uso do atributo sweetness ajudou a destacar o embasamento do rifte, enquanto a amplitude RMS, o cosseno da fase e a impedância acústica relativa, foram cruciais para determinar a arquitetura principal das unidades do Grupo Lagoa Feia e definir a principal fácies sísmica. A seguir são descritos os atributos utilizados, suas competências na análise faciológica e quais foram as aplicabilidades no mapeamento (Radovich \& Oliveros, 1998; Chopra \& Marfurt, 2007).

Sweetness: o sweetness é derivado matematicamente, dividindo a intensidade de reflexão (também conhecido como "amplitude instantânea ou envelope" ou "envelope de amplitude") pela raiz quadrada da frequência instantânea. Intensidade de reflexão é uma amplitude independente de atributos de fase, e é sempre positiva, tendo a mesma gama de valores e amplitude de onde é derivada. A frequência instantânea é a taxa da mudança de fase, é medida em hertz, e está relacionada tanto ao comprimento de banda da sísmica quanto à espessura da camada. Como consequência, esse atributo é extremamente sensível à variação da frequência de amplitude dependente (Chopra \& Marfurt, 2007). Com ele, através do uso dos contrastes claros e escuros foi possível o mapeamento da seção rifte. Nessa análise sísmica este atributo tem se mostrado muito eficiente no mapeamento do topo das unidades vulcânicas de todo pacote de dados (Fig. 4).

Cosseno da fase: a fase instantânea é definida para qualquer sinal complexo. 0 cosseno da fase deriva estritamente disso, representando o cosseno da fase instantânea. Esse atributo é de grande importância já que determina a localização de eventos no traço sísmico e leva ao cálculo de outras grandezas instantâneas. 0 cosseno da fase deixa grandes eventos mais claros e é eficiente em salientar descontinuidade nos refletores, falhas, pinch-outs, angularidades, mudanças no acamadamento (Chopra \& Marfurt, 2007) limites de sequências sísmicas, padrões de acamadamento sedimentar e regiões com padrão onlap/offlap normalmente são exibidos com maior clareza. Para a delimitação das unidades é usado o limite entre os padrões. Neste trabalho o cosseno da fase foi utilizado para estabelecer a continuidade do padrão dos refletores e visualização de falhas (Fig. 4).

Amplitude RMS: é definida como a cobertura da amplitude do sinal calculado pela raiz da soma dos componentes imaginários e reais do sinal, similar a intensidade de reflexão. Porém, no Amplitude RMS se destaca as anomalias de amplitude dentro dos conjuntos de dados sísmicos (Chopra \& Marfurt, 2007). Portanto, ocorre a transformação de picos e calhas do sinal sísmico em positivo e background (próximo a zero) em negativo. Nesta análise sísmica este atributo possibilitou a melhor visualização das fácies sísmicas principalmente para os carbonatos e evaporitos e o mapeamento da base do sal (Fig. 4).

Impedância acústica relativa: é resultado de uma simples integração do sinal complexo. Representa a aproximação do componente de maior frequência da impedância acústica relativa (Chopra \& Marfurt, 2007). Através da inversão de picos e calhas ocorre a ampliação da frequência da reflexão e assim, realça a textura. Este atributo mostrou-se extremamente eficiente em destacar as texturas sísmicas das variadas subunidades reconhecidas e mapeadas dentro da seção sin-rifte e o reconhecimento das litofácies carbonáticas e evaporíticas (Fig. 4).

A figura 4 apresenta uma síntese das regras de interpretação para cada atributo utilizado, assim como sua aplicabilidade e expressão visual no intervalo analisado.

\section{Resultados}

\subsection{Reconhecimento das texturas sísmicas na Bacia de Campos}

Textura sísmica é aqui definida por uma combinação da geometria de refletores (continuidade e terminação de refletores), propriedades de amplitude e espessura sísmica do principal refletor analisado. Utiliza-se uma técnica de análise de imagem sísmica, mapeando tanto a amplitude normal quanto os atributos complexos do sinal, definidos tanto pela fase instantânea quanto pelo cosseno da fase. Esses dois atributos, combinados com o mapeamento usual das terminações de refletores, foram de grande utilidade para destacar camadas delgadas, a continuidade entre os diversos refletores e as terminações de refletores (Fig. 5). Para apurar a calibração da textura interna, 
foram extraídos atributos sísmicos relacionados à amplitude relativa e contraste de impedância, como a intensidade da reflexão e impedância acústica relativa.

Usando a combinação de atributos e os critérios aqui descritos, foram reconhecidas três texturas sísmicas principais, que se repetem sistematicamente. Uma síntese é apresentada na Fig. 6, onde as principais características de cada unidade sísmica são brevemente descritas, fornecendo também uma referência para sua representação sísmica.

Textura sísmica 1: é definida por refletores caóticos e de baixa amplitude, seguidamente danificados por pequenas falhas ou fraturas. Essa unidade é sistematicamente justaposta a um plano de falha ao longo de toda a sua ocorrência. Nos atributos sísmicos impedância acústica relativa e cosseno da fase os refletores ocorrem com um padrão caótico (Fig. 5A e B).

Textura sísmica 2: é caracterizada por refletores fortes a médios, semicontínuos, com baixa amplitude e pouco espessos. É identificada seguidamente por anomalias de amplitude, com uma geometria de leve espessamento lateral e onlap. Esta textura é também observada no atributo sísmico impedância acústica relativa (Fig. 5A), apresentando um padrão granular e sinal pontilhado em claro contraste com a textura sísmica 3. No atributo sísmico cosseno da fase apresenta um padrão menos marcado e não contínuo dos refletores (Fig. 5B).

Textura sísmica 3: observada em toda a unidade sin-rifte, é caracterizada por refletores muito contínuos, intensos e espessos, intercalados com as unidades de finas camadas da textura sísmica 2 . Esta textura é bem típica, claramente visível, e não apresenta onlap ou espessamento lateral. Utilizando o atributo sísmico impedância acústica relativa se observa que os refletores ocorrem contínuos, espessos e brilhantes (Fig. 5A). Da mesma forma, no atributo sísmico cosseno da fase, os refletores se mostram contínuos, mais espessos e com limites abruptos (Fig. 5B).

Um exemplo da aplicação e classificação das texturas sísmicas proposta está apresentado na figura 6, com o mapeamento das texturas na linha sísmica II usando para correlação o poço B. Os números 1 a 3 representam as diferentes texturas sísmicas descritas.

\begin{tabular}{|c|c|c|c|}
\hline Atributo sísmico & Utilidade & $\begin{array}{c}\text { Regras de } \\
\text { interpretação }\end{array}$ & Expressão visual \\
\hline Sweetness & $\begin{array}{l}\text { Usar os contrastes claros } \\
\text { e escuros para o } \\
\text { mapeamento da seção } \\
\text { rifte }\end{array}$ & $\begin{array}{l}\text { Usar o limite entre as } \\
\text { áreas claras e escuras }\end{array}$ & \\
\hline Cosseno da Fase & $\begin{array}{l}\text { Estabelecer continuidade } \\
\text { do padrão dos refletores e } \\
\text { visualização de falhas }\end{array}$ & $\begin{array}{l}\text { Usar o limite entre os } \\
\text { padrões }\end{array}$ & \\
\hline Amplitude RMS & $\begin{array}{l}\text { Melhoramento visual das } \\
\text { fácies sísmicas } \\
\text { - principalmente para } \\
\text { carbonatos e evaporitos } \\
\text { - mapeamento da base do } \\
\text { sal }\end{array}$ & $\begin{array}{l}\text { Transforma picos e } \\
\text { calhas do sinal símico } \\
\text { em positivo e } \\
\text { background (próximo a } \\
\text { zero) em negativo }\end{array}$ & \\
\hline $\begin{array}{l}\text { Impedância } \\
\text { acústica } \\
\text { relativa }\end{array}$ & $\begin{array}{l}\text { Melhoramento visual das } \\
\text { fácies sísmicas } \\
\text { - principalmente para } \\
\text { carbonatos e evaporitos } \\
\text { - mapeamento da base do } \\
\text { sal } \\
\text { - juntamente com o } \\
\text { atributo cosine phase, } \\
\text { mapeamento das falhas }\end{array}$ & $\begin{array}{l}\text { - Inversão de picos e } \\
\text { calhas } \\
\text { Pico: }(-) \\
\text { Calha: }(+) \\
\text { - Amplia a frequência da } \\
\text { reflexão } \\
\text { - Realça a textura }\end{array}$ & \\
\hline
\end{tabular}

Figura 4. Síntese das regras de interpretação dos atributos sísmicos e sua utilidade geológica na análise da textura sísmica. 

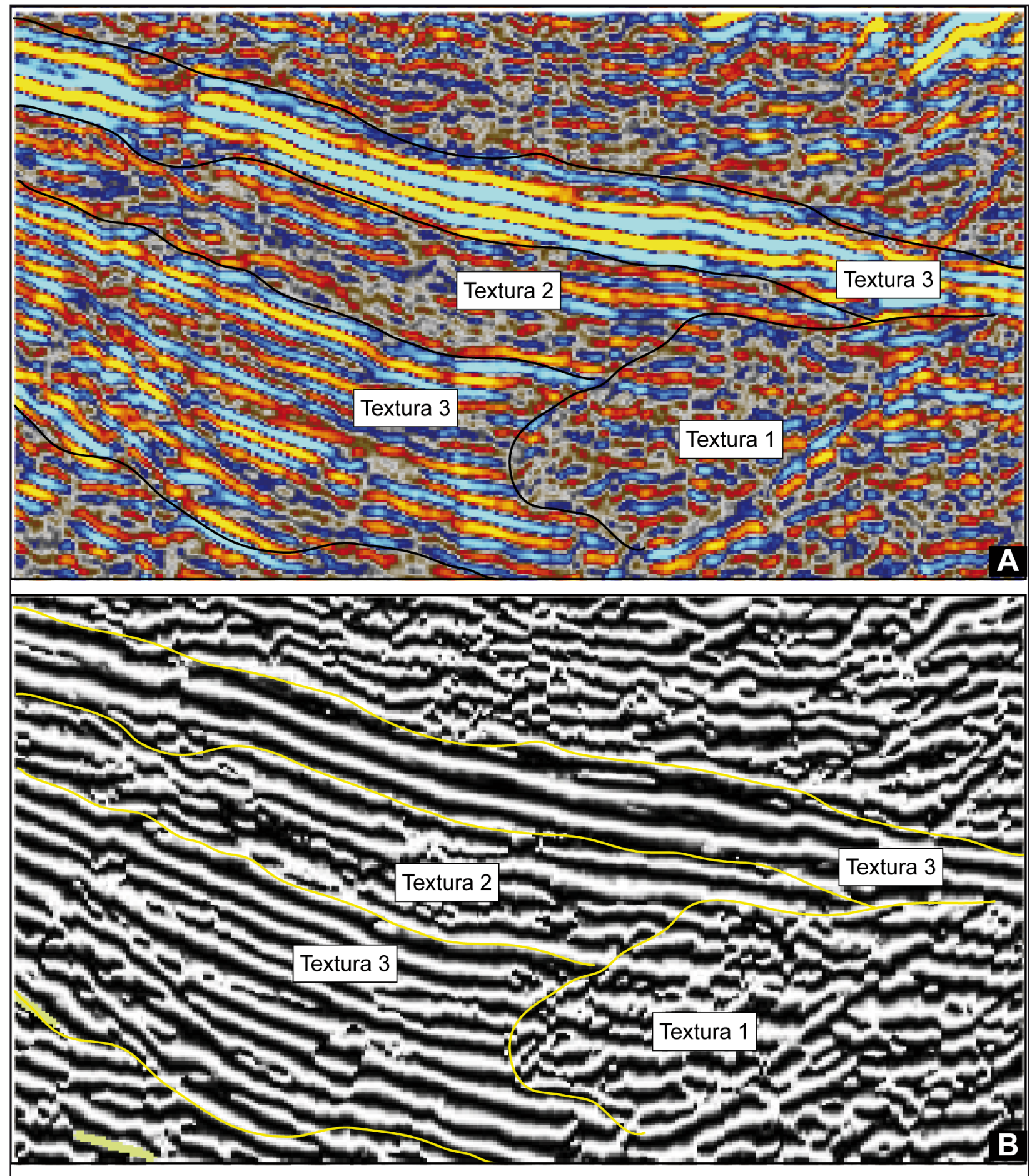

Figura 5. Atributos sísmicos na linha sísmica II. A) Atributo sísmico Impedância acústica relativa. B) Atributo sísmico cosseno da fase.

\subsection{Calibração das texturas sísmicas com informa- ções litológicas de poços}

Foram utilizados para a calibração das texturas sísmicas dois poços (A e B) na Bacia de Campos com dados litológicos (amostras de calha), checkshot e que são perfurados até a Formação Cabiúnas. Desta forma, o uso destes poços possibilitou melhor robustez à calibração com as texturas sísmicas. Os dados litológicos dos poços A e
B foram correlacionados com as texturas sísmicas delimitadas e assim foi possível determinar a composição litológica das texturas sísmicas. No entanto, a composição litológica das texturas sísmicas é representada pela litologia dominante que ocorre no intervalo. Desta forma, os grupos litológicos são determinados da seguinte maneira: Textura Sísmica 1: depósitos de falha de borda, compreendem sedimentos conglomeráticos, folhelhos e carbonatos. 0 poço A perfura a porção distal destes depó- 


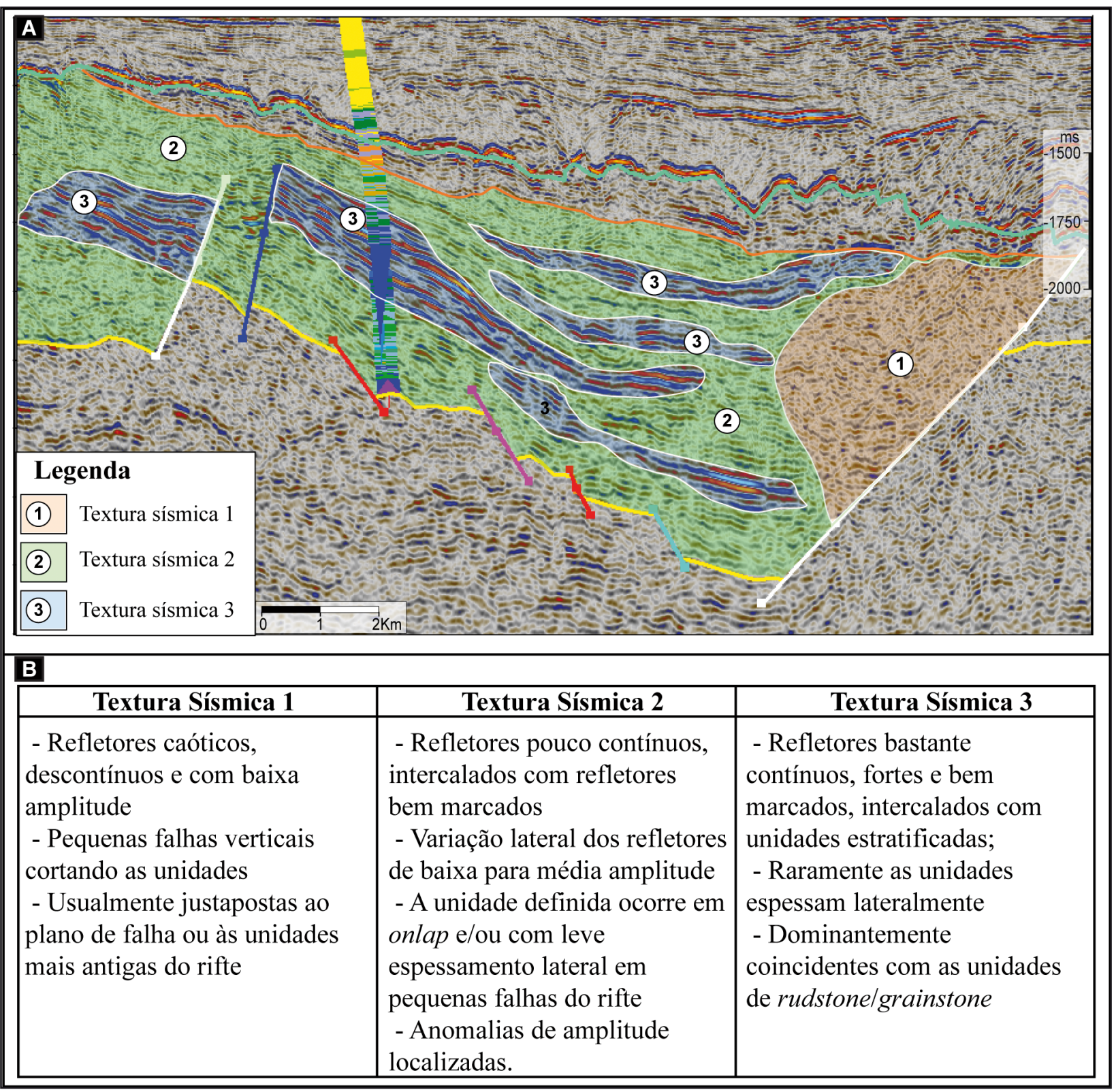

Figura 6. Linha sísmica II e poço B mostrando as texturas sísmicas definidas (A) e descrição das texturas sísmicas observadas (B).

sitos, visto que estes estão sempre associados com falhas de borda. Textura Sísmica 2: depósitos de sedimentos finos, compreendem sedimentos como margas, folhelhos, arenitos, calcilutitos. Os poços A e B perfuram estes sedimentos em sua integridade nas texturas sísmicas. Textura Sísmica 3: depósitos de Rudstones e Grainstones, compreendem sedimentos carbonáticos grossos como coquinas e calcarenitos. Os poços A e B perfuram estes sedimentos em sua integridade, sendo que o poço $B$ apresenta os padrões texturais em sísmica mais típico para esta textura sísmica.

Poço A: As unidades azuis, caracterizadas pelos refletores grossos, representam principalmente rochas carbonáticas (rudstones/grainstones), enquanto a alternância de unidades laranja/verde representa as unidades de arenitos/folhelhos, constituindo a maior parte da textura sísmica 2 . Por fim, a cunha mapeada da textura sísmica 1 é composta dominantemente por conglomerados (dominantemente vulcanoclásticos no testemunho utilizado para calibração), unidades laranja no perfil composto (Fig.7A).

Poço B: Como mostrado na figura 7B, foi possível reconhecer, através dos dados litológicos, a natureza dos principais refletores. Isso permitiu caracterizar pelo menos duas das principais texturas sísmicas. As reflexões intensas e contínuas correspondem no poço a calcirruditos (unidades em azul). Basicamente, esta calibração ajudou a definir as unidades que fazem parte da textura sísmica 3 como sedimentos carbonáticos. A outra textura sísmica que circunda os refletores grossos, caracterizada por camadas finas e refletores 
que espessam lateralmente (textura sísmica 2), é representada pela alternância de sedimentos finos (siltitos, calcilutitos e folhelhos - unidades verdes e azuis claras).

Desta forma, com a adição dos dados litológicos dos poços A e B, informação da geometria dos refletores com os atributos sísmicos e informações das texturas sísmicas podemos definir os ambientes deposicionais que influenciaram os tipos de depósitos (e.g. unidades carbonáticas, arenitos e outras unidades que possam ter sido depositadas) e assim, ter um reconhecimento das sismofácies. Sismofácies é um conceito originalmente proposto por Brown Jr. \& Fisher (1977) caracterizado como uma unidade tridimensional, com uma área defi- nida, constituída por reflexões sísmicas cujos parâmetros inerentes diferem das fácies adjacentes. Uma sismofácies é o registro nas reflexões sísmicas dos fatores geológicos que as geram, tais como: tipo de litologia, estratificação, feições deposicionais, etc.

\section{Discussão dos resultados}

\subsection{Comparação entre o mapeamento das sismofá- cies nas bacias de Campos e Santos}

A caracterização das sismofácies nas bacias de Campos e Santos se baseou nos parâmetros dos

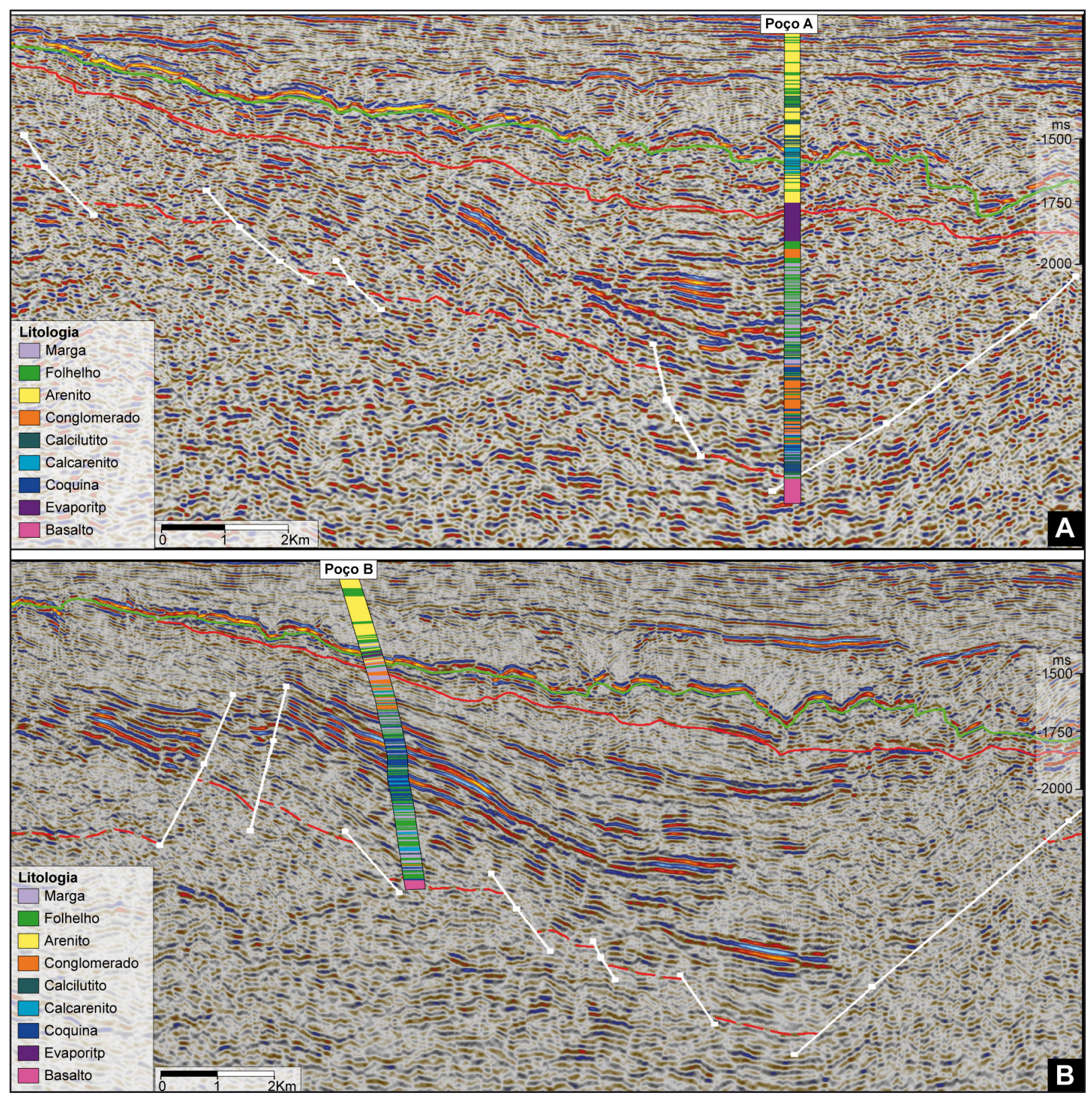

Figura 7. Linha sísmica e poços mostrando a assinatura das litologias nos refletores sísmicos. A) Linha sísmica IV e Poço A (localização ver na figura 1) e B) Linha sísmica II e Poço B (localização ver na figura 1). 
refletores sísmicos, continuidade, amplitude e frequência. No entanto, para fins de correlação com os dados litológicos foram utilizados na Bacia de Santos os mesmos dados litológicos usados na Bacia de Campos. A Bacia de Santos possui poucas referências de poços na Seção Rifte e no conjunto de dados adquiridos não há nenhum poço para utilizar como parâmetros de comparação. Desta forma, na Bacia de Santos a análise litológica foi realizada de forma especulativa, sem nenhuma confirmação final com os dados de rocha. Tendo em vista diminuir os efeitos desta análise foi efetuada uma comparação das sismofácies entre as bacias de Campos e Santos (Fig. 8 e fig. 9).

Assim como na Bacia de Campos, na Bacia Santos foram identificadas três principais sismofácies: Sismofácies 1 (depósitos de falhas de borda, textura sísmica 1), Sismofácies 2 (depósitos de sedimentos finos, textura sísmica 2), e Sismofácies 3 (grainstones e rudstones, textura sísmica 3) (Fig. 8). Para uma melhor observação das sismofácies nas linhas das bacias de Campos e Santos, elas estão apresentadas nas figuras 10, 11 e 12 .

A Sismofácies 1 é interpretada como os depósitos de falha de borda, compostos dominantemente por conglomerados originados pela erosão decorrente da elevação do bloco de footwall da falha de borda (Ene et al., 2015). Os refletores são caóticos, de baixa amplitude e sem continuidade (Ene et al., 2015; Ramirez et al., 2015). Na linha VI, são claros os avanços e recuos dos depósitos, bem como suas geometrias inclinadas, associadas a processos gravitacionais. Já na linha V (Fig. 9D), as sismofácies também se encontram encaixadas nas falhas de borda, mas com uma dimensão reduzida. Isso pode ser interpretado como: (i) uma atividade tectônica menor nestas falhas, quando comparada com a atividade tectônica das outras falhas, tanto na Bacia de Campos, quanto na linha VI da Bacia de Santos; (ii) uma baixa taxa de erosão associada a estas regiões, onde algum fator climático local ou deste período de atividade fez com que a erosão destas escarpas altas não apresentasse depósitos expressivos; (iii) a erosão do bloco alto produziu sedimentos finos, onde o produto da erosão e transporte gravitacional, devido ao tipo de área-fonte, acabou por produzir um alto teor de sedimentos finos, que se misturam com facilidade com a sismofácies 2 , fazendo com que os depósitos grossos típicos da sismofácies 1 apresentem uma área reduzida ao longo da falha de borda; ou (iv) uma variação complexa entre os três itens anteriormente citados. Somente com uma amostragem bem ampla e confiável (testemunhos) seria possível para determinar a efetiva restrição destes de- pósitos de falha de borda na linha V. Este mesmo efeito é observado na linha VII (Fig. 9E), mas mais evidente, já que a falha de borda da linha VI possui um rejeito maior que a da linha $V$. De mesma forma, a textura típica da sismofácies 1 encontra-se bem reduzida, e os mesmos possíveis fatores controladores podem ser elencados: menor atividade tectônica, baixa taxa de erosão, erosão do bloco alto produzindo apenas sedimentos finos, ou uma relação complexa entre estes. A comparação textural da sismofácies 1 entre as Bacias de Campos e Santos (Fig. 10) mostra o grau de semelhança entre a textura sísmica em fase normal, cosseno da fase, Amplitude RMS e Impedância acústica relativa, onde observa-se baixa continuidade, baixa amplitude e frequência, com zonas de ruído no cosseno da fase, zonas brancas na Amplitude RMS e ruídos na Impedância acústica relativa.

A Sismofácies 2 (Depósitos de sedimentos finos), que compreende os depósitos ressedimentados dominados por grãos finos e os sedimentos finos de background lacustre (Ene et al., 2015), indivisível devido a sua semelhança textural, também foi amplamente identificada na Bacia de Santos (Fig. 9C, D e E), com as mesmas texturas da Bacia de Campos, ou seja, baixa continuidade e baixa amplitude das reflexões, envolvendo e gradando lateralmente para a sismofácies 3 , com ampla dominância ao longo da seção (Ene et al., 2015; Ramirez et al., 2015). Entretanto, algumas reflexões bem finas e isoladas apresentaram uma continuidade maior e amplitude mais intensa nas linhas da Bacia de Santos, mas assim mesmo foram incluídas na sismofácies 2 por não apresentarem as características bem distintas da sismofácies 3 . A comparação textural da sismofácies 2 entre as Bacias de Campos e Santos (Fig. 11) mostra o grau de semelhança entre a textura sísmica em fase normal, cosseno da fase, Amplitude RMS e Impedância acústica relativa, onde se observa a baixa continuidade e baixa amplitude na fase normal, mas com traços mais contínuos no cosseno da fase, um total blanking na Amplitude RMS, e zonas mais contínuas mas de baixa amplitude na Impedância acústica relativa.

A Sismofácies 3 (Grainstones e rudstones), que compreende exclusivamente os depósitos ressedimentados dominados por grãos grossos (Ene et al., 2015), ocorre na Bacia de Santos da mesma forma que na de Campos, como ocorrências restritas, englobadas pela sismofácies 2, e frequentes gradações laterais para a sismofácies 2 (Ene et al., 2015; Ramirez et al., 2015) (Fig. 9C, D e E). A comparação textural da sismofácies 3 entre as Bacias de Campos e Santos (Fig. 12) mostra o grau de semelhan- 


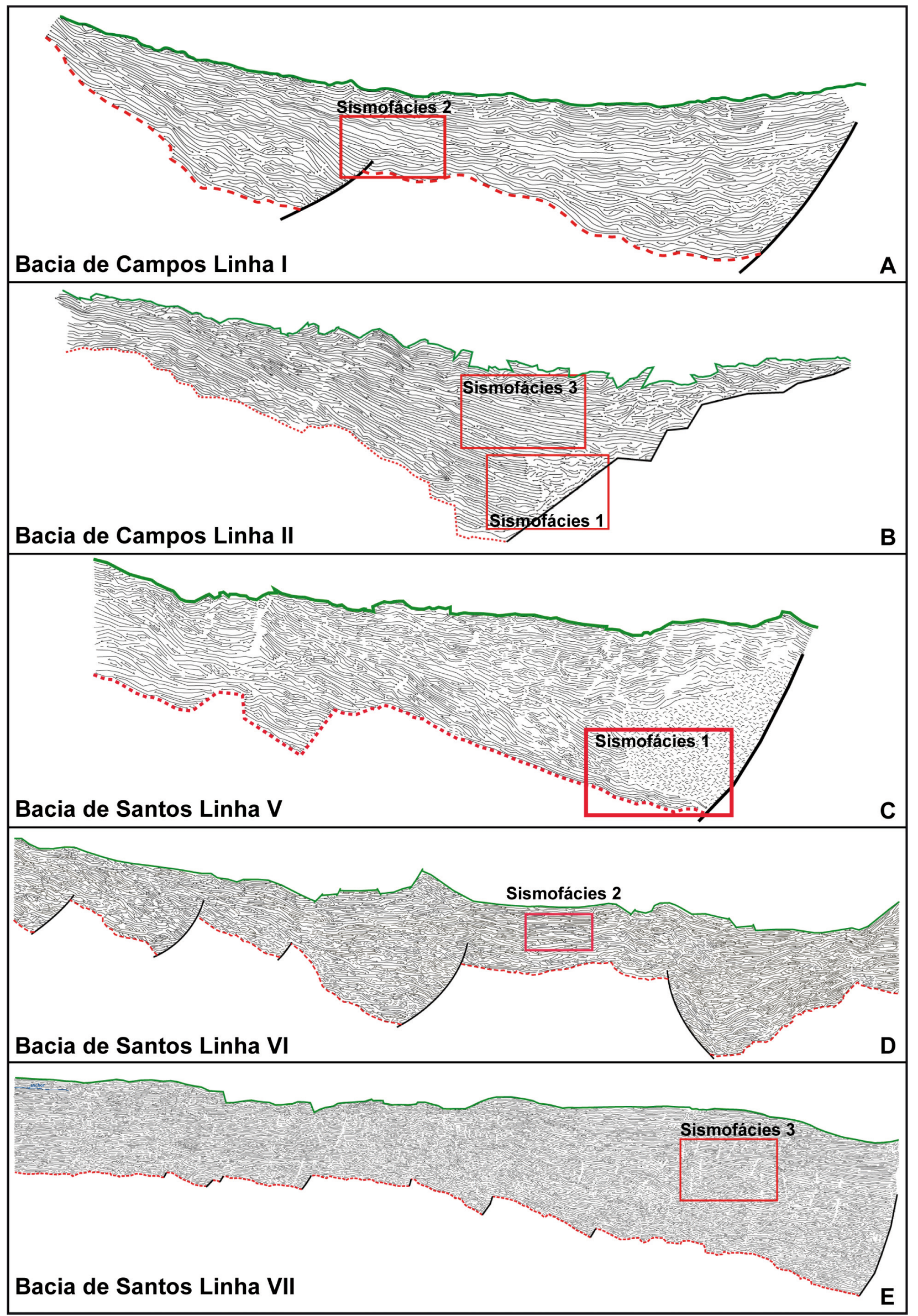

Figura 8. Localização dos painéis comparativos das sismofácies reconhecidas nas Bacias de Campos e Santos em suas respectivas linhas sísmicas (A à E). 


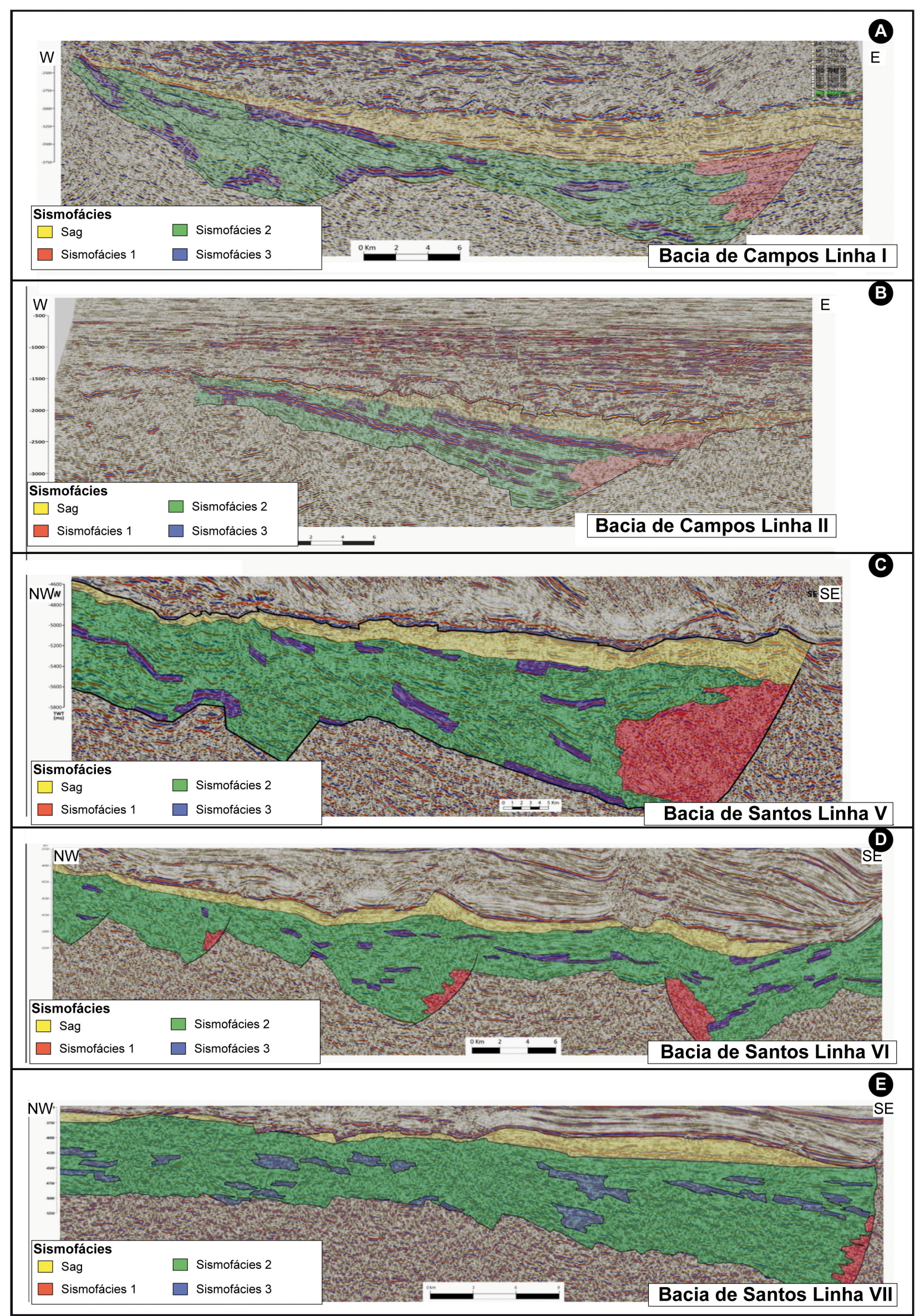

Figura 9. Mapeamento das sismofácies nas linhas sísmicas nas bacias de Campos e Santos (A à E). 


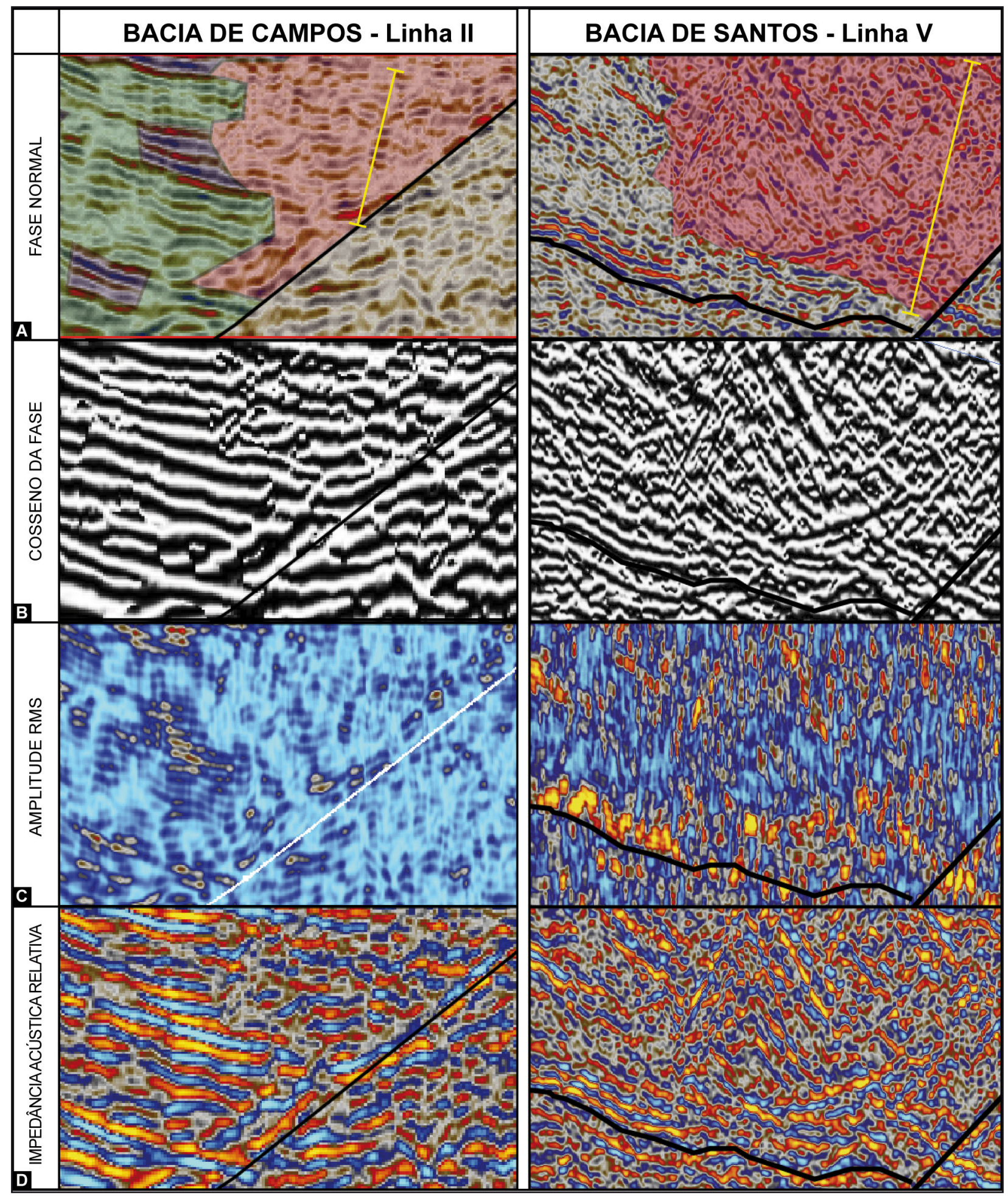

Figura 10. Painel comparativo da sismofácies 1 nas Bacias de Santos e Campos, em fase normal (A), cosseno da fase (B), Amplitude RMS (C), e Impedância acústica relativa (D).

ça entre a textura sísmica em fase normal, cosseno da fase, Amplitude RMS e Impedância acústica relativa, onde observa-se a alta continuidade e alta amplitude e frequência na fase normal, a continuidade bem definida e alta frequência no cosseno da fase, as zonas de bright spot na Amplitude RMS, e a continuidade bem definida e alta amplitude na Impedância acústica relativa. Adicionalmen- te, a sismofácies 3 na Bacia de Santos ocorre da mesma forma aleatória que na Bacia de Campos, tanto nas zonas altas de margem flexural, quanto nas zonas profundas próximas do depocentro do meio-gráben, sem nenhum padrão específico, com frequentes gradações laterais tanto no sentido deposicional dip como no strike. 0 que diferencia a sismofácies 3 nas Bacias de Santos e Campos é a 
dimensão bidimensional e a frequência de ocorrência da sismofácies. Na Bacia de Santos a sismofácies 3 ocorre menos frequentemente e com dimensões menores, sugerindo que os depósitos ressedimentados dominados por grãos grossos na Bacia de Santos são menos frequentes e menos possantes.

Observando a figura 9A e B temos que na Bacia de Campos a sismofácies 3 mostra refletores de alta amplitude, comumente espessos e contínu- os, porém apresentam uma configuração ondulada com refletores formando mounds do meio para o topo. A distribuição desta sismofácies ocorre bem definida, com ampla continuidade lateral, mas com distribuição um tanto aleatória, com gradações laterais para a sismofácies 2 tanto para oeste quanto para leste. 0 mesmo padrão se repete no meio-gráben leste, com ocorrências centralizadas dos grainstones e rudstones sem nenhum controle de variação bem definida entre as sismofácies

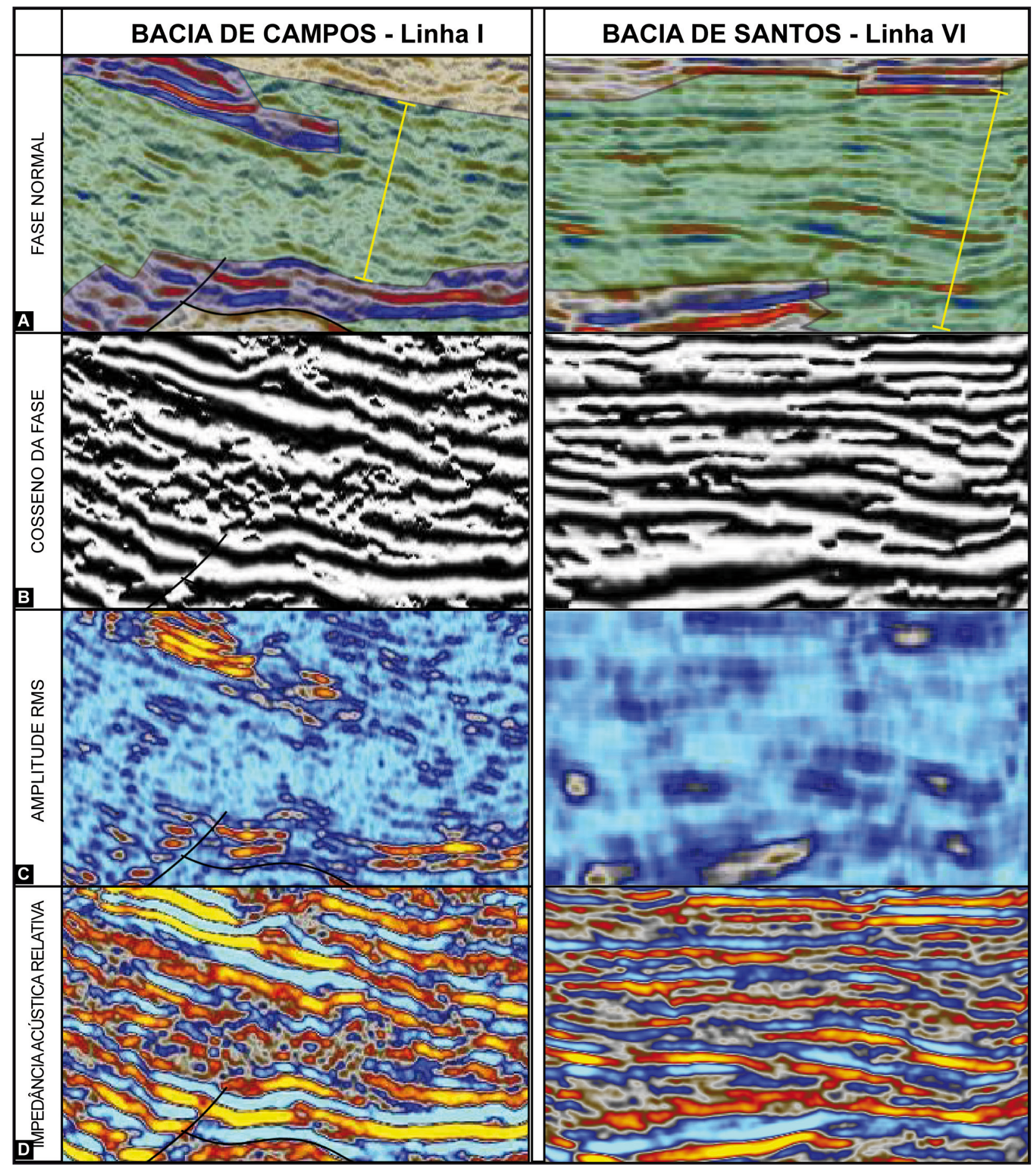

Figura 11. Painel comparativo da sismofácies 2 nas bacias de Santos e Campos, em fase normal (A), cosseno da fase (B), Amplitude RMS (C), e Impedância acústica relativa (D). 


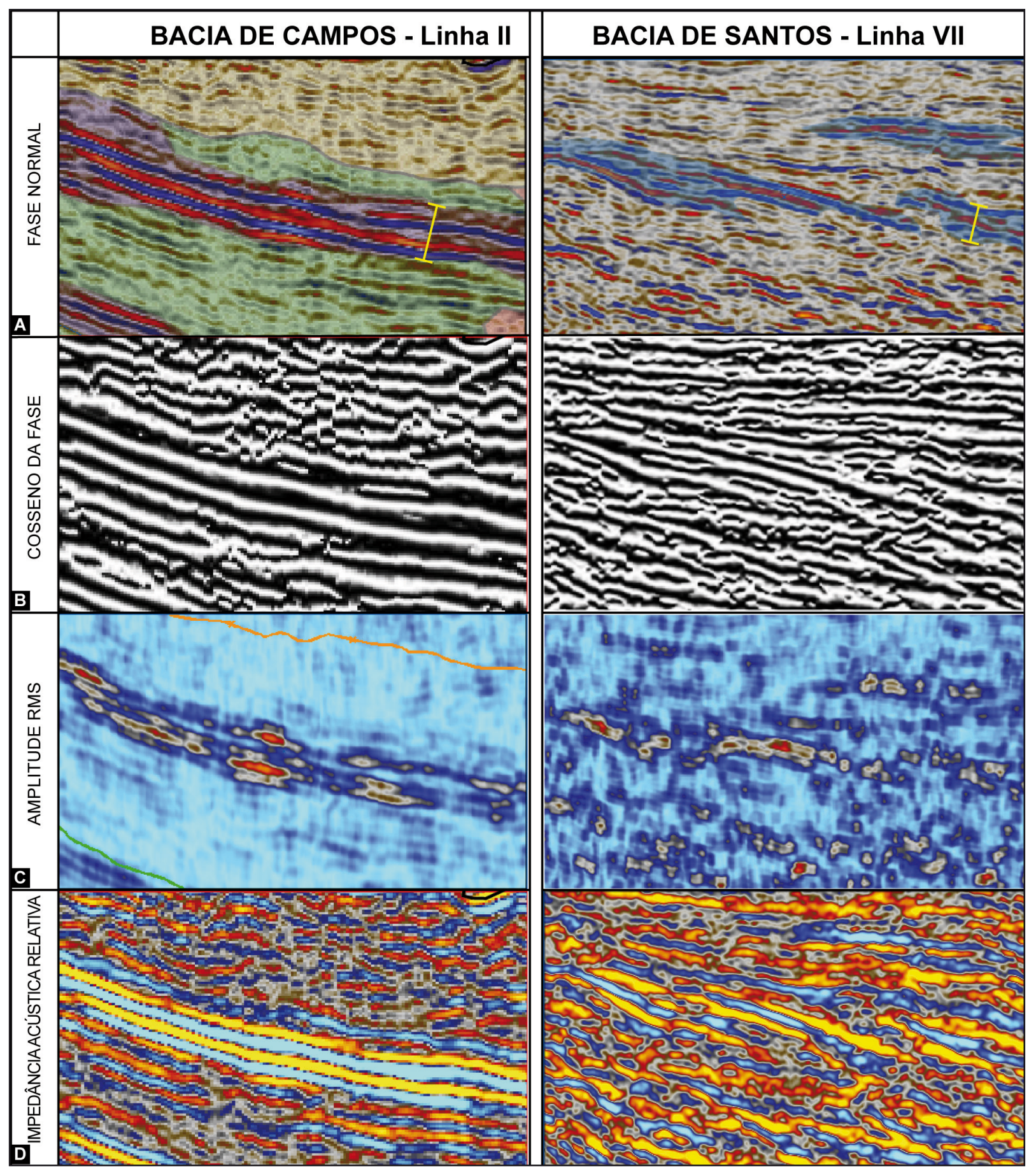

Figura 12. Painel comparativo da sismofácies 3 nas bacias de Santos e Campos, em fase normal (A), cosseno da fase (B), Amplitude RMS (C), e Impedância acústica relativa (D)..

(Fig. 9A e B). 0 mesmo padrão se repete no meio-gráben leste, com ocorrências centralizadas dos grainstones e rudstones sem nenhum controle de variação bem definida entre as sismofácies (Fig. 9A). Enquanto que na figura 9C, D e E temos que na Bacia de Santos a sismofácies 3 apresenta refletores de alta amplitude, comumente delgados e pouco contínuos. A distribuição desta sismofácies ocorre em um padrão que grada da margem flexural para o depocentro do meio-gráben, sem apresentar um padrão de empilhamento, ocorrendo de forma aleatória espacial e temporalmente (Fig. 9C, $\mathrm{D}$ e E), e por vezes concentrada do centro à porção sudeste da bacia e no depocentro da calha, próximas à falha de borda (Fig. 9D e E). 


\section{Conclusões}

A aplicação da metodologia aqui proposta, compreendendo a caracterização de fácies sísmicas, com o suporte de atributos sísmicos, forneceu confiáveis definições de composições litológicas dominantes para a Bacia de Campos. Esta aplicação fez-se necessária devido à baixa qualidade do imageamento sísmico sub-sal, pois este intervalo de estudo além de apresentar perda de sinal sísmico pelo sal encontra-se em seções profundas e de difícil visualização sísmica. Assim, a correlação de informações de poço com dados de sísmica 2D é fundamental para a compreensão do significado de cada fácies sísmica. Embora existam dados sísmicos recentes com imageamentos mais avançados e boa definição nestes níveis profundos da bacia, a presente proposta de estudo fornece subsídios para obter informações no grande volume de dados 2D disponíveis, tanto na Bacia de Campos, quanto Santos. Na seção profunda das bacias foi possível obter assinaturas das texturas sísmicas e posteriormente correlacionar com os dados litológicos com base em perfis compostos de dois poços. Desta forma, mesmo com dados 2D e com distribuição espacial esparsa, algumas inferências de boa qualidade podem ser alcançadas. 0 ponto-chave é integrar e trabalhar em uma troca de informações nos dois sentidos, entre a análise estratigráfica e os processos de modelagem sísmica.

Já na Bacia de Santos, onde não se obteve dados de poços, a análise litológica e sua correlação com as sismofácies, tem um caráter mais especulativo. Para contornar este problema foi realizada uma comparação das sismofácies entre as bacias de Campos e Santos. Desta forma, o resultado adquirido proporciona um ponto de início para observações mais detalhadas sobre as sismofácies reconhecidas na Bacia de Santos.

Por fim, a exploração de hidrocarbonetos na

Bacia de Campos encontra-se bem estabelecida, com diversos intervalos produtores, compreendendo as recentes descobertas do pré-sal, os turbiditos do Cretáceo Superior, e os carbonatos e coquinas da seção rifte, sendo que estes produzem desde a década de 1970 (Abrahão et al., 1990). Desta forma, o reconhecimento da sismofácies 3, relacionada aos rudstones e coquinas produtoras da Bacia de Campos, permite uma visualização de novos níveis nunca antes explorados na seção rifte da Bacia de Campos, e aponta para a possibilidade de encontrar estes mesmos corpos carbonáticos na Bacia de Santos, em condições até mais favoráveis, pois apresentam profundidades de ocorrência mais rasas.
Agradecimentos - Este estudo constitui parte da tese de doutorado da primeira autora (RA) junto ao Programa de Pós-graduação em Geociências da UFRGS, integrada ao Projeto Deep Rift, desenvolvido em parceria entre a UFRGS e a BG Brasil, amparado pela Lei do Petróleo. Agradecemos especialmente ao Global Technology Centre da BG Brasil pelo apoio financeiro e contribuições técnicas ao projeto. Adicionalmente, à ANP pelo compromisso com investimentos em pesquisa e desenvolvimento.

\section{Referências}

Baumgarten, C.S., Dultra, A.J., Scuta, M.S., Figueiredo, M.V. \& Sequeira, M.F.P.B. 1988. Coquinas da Formação Lagoa Feia, Bacia de Campos: Evolução da Geologia de Desenvolvimento. Boletim de Geociências da Petrobras, Rio de Janeiro. 2(1): 27-36.

Chang, H.K., Kowsmann, R.O., Figueiredo, A.M.F. \& Bender, A. 1992. Tectonics and stratigraphy of the East Brazil Rift system: an overview. Tectonophysics, 213: 97-138.

Chopra, S. \& Marfurt, K.J. 2007. Seismic attributes for prospect identification and reservoir characterization. Tulsa, OK, SEG books, 464p.

Ene, P., Kuchle, J., Alvarenga, R.S., Iacopini, D., Goldberg, K. 2015. Evolução complexa de um meio-gráben: seção rifte da Bacia de Campos baseada em análise sismoestratigráfica. Pesquisas em Geociências, 42(1): 45-60.

Gao, D. 2003. Volume texture extraction for 3D seismic visualization and interpretation: Geophysics, 68: 1294-1302.

Gao, D., 2007. Application of three-dimensional seismic texture analysis with special reference to deep-marine facies discrimination and interpretation: Offshore Angola, West Africa. AAPG Bulletin, 91: 1665-1683

Guardado, L.R., Spadini, A.R., Brandão, J.S.L. \& Mello, M.R. 2000. Petroleum System of the Campos Basin, Brazil. In: Mello, M.R., Katz, B.J. (Eds.). Petroleum systems of South Atlantic margins. AAPG Memoir 73:317- 324.

Haralick, R.M., Shanmugam, K., \& Dinstein, I. 1973, Textural features for image classification. IEEE Transactions on Systems, Man and Cybernetics, 3: 610-621.

Milani, E.J. \& Thomaz Filho, A. 2000. Sedimentary Basins of South America. In: Cordani, U.G., Milani, E.J., Thomaz Filho, A. \& Campos, D.A (Eds.). Tectonic Evolution of South America. Rio de Janeiro, p. 389-449.

Moreira, J.L.P., Madeira, C.V., Gil, J.A. \& Machado, M.A.P. 2007. Bacia de Santos. Boletim de Geociências da Petrobras, 15(2): 531-549.

Posamentier, H.W., Jervey, M.T. \& Vail, P.R. 1988. Eustatic Controls on Clastic Deposition I - Conceptual Framework. In: Wilgus, C.K., Hastings, B.S., Kendall, Posamentier, H.W., Ross, C.A. \& Van Waggoner, J.C. (Eds.). SEPM Special Publication, 42 - Sea-level changes: an integrated approach. Tulsa, SEPM Strata Society for Sedimentary Geology, p. 109-124. 
Prather B.E., Booth J.R., Steffens G.S, \& Craig P.A. 1998. Classification, Lithologic Calibration, and Stratigraphic Succession of Seismic Facies of Intraslope Basins, Deep-Water Gulf of Mexico. AAPG Bulletin, 82: 701-728.

Ramirez, A.A., Kuchle, J., Alvarenga, R.S., Scherer, C., Goldberg, K. 2015. Análise sismoestratigráfica da seção rifte da Bacia de Santos, Brasil. Pesquisas em Geociências, 42(3): 263-280.

Rangel, H.D., Martins, F.A.L., Esteves, F.R. \& Feijó, F.J. 1994. Bacia de Campos. Boletim de Geociências Petrobrás, 8(1): 203-217.

Reed IV, T.B. \& Hussong, D. 1989. Digital image processing techniques for enhancement and classification of SeaMARC II Side Scan Sonar Imagery. Journal of Geophysical Research, 94: 7469-7490

Radovich, B. J., \& Oliveros, R.B. 1998. 3-D sequence interpretation of seismic instantaneous attributes from the Gorgon field: The Leading Edge, 17: 1286-1293.

Vinther, R., K. Mosegaard, K. Kierkegaard, I. Abatzis, C. Andersen, O. Vejbaek, F., \& P. Nielsen, 1995. Seismic texture classification: A computer-aided approach to stratigraphic analysis. In: ANNUAL INTERNATIONAL MEETING,65 Society of Exploration Geophysicists Expanded Abstracts, v. 95, p. 153-155.

Weszka, J., Dyer, C.\& Rosenfeld, A., 1976. A comparative study of texture measures for terrain classification. IEEE Transactions on Systems, Man and Cybernetics. 6: 269-285.

Zhang, Z., \& M. Simaan, 1989. Knowledge-based reasoning in SEISIS: A rules-based system for interpretation of seismic sections based on texture, In: F. Aminzadeh \& M. Simaan, (Eds). Expert systems in exploration: Society of Exploration Geophysicists Geophysical Development Series, 3: 141-159.

Editores: César L. Schultz \& Paulo A. Souza. 
